\title{
High genetic diversity and rapid spread of peste des petits ruminants virus Asian lineage IV in Nigeria
}

\author{
Samuel Mantip ${ }^{1}$, Anthony Sigismeau ${ }^{2}$, David Shamaki ${ }^{3}$, Genevieve Libeau ${ }^{4}$, Souaibou \\ Farougou $^{5}$, and Arnaud Bataille ${ }^{6}$ \\ ${ }^{1}$ National Veterinary Research Institute, Vom. \\ ${ }^{2}$ ASTRE, Univ Montpellier, CIRAD, INRA, Montpellier, France. \\ ${ }^{3}$ NVRI, Vom \\ ${ }^{4}$ CIRAD \\ ${ }^{5}$ University of Abomey-Calavi. 01 BP 2009, Cotonou. \\ ${ }^{6}$ CIRAD Departement Systemes biologiques
}

September 11, 2020

\begin{abstract}
Peste des Petits Ruminants (PPR) is a highly contagious viral disease that mainly affects goats and sheep in Asia, Africa and the Middle East. The PPR virus (PPRV) can be classified into four genetically distinct lineages (I, II, III, and IV). All have been historically present in Africa, except the Asian lineage IV that has been spreading across the globe and Africa for the last decades. Previous studies have identified the presence of the lineage IV in Nigeria since 2010. In this study, samples were taken from 268 small ruminants with PPR symptoms across Nigeria in 2017-2018 to provide an update on the distribution and genetic diversity of the lineage IV in the country. Sequence from a portion of the PPRV nucleoprotein (N) gene could be obtained from 72 samples, and all but one belonged to lineage IV. Phylogenetic analysis identified at least 5 lineage IV sub-clusters in Nigeria, re-grouping samples across multiple regions. Our results suggest an extensive endemic circulation of PPRV lineage IV across Nigeria and across borders with neighbouring countries, highlighting the difficulty of the control of this disease in the region.
\end{abstract}

\section{INTRODUCTION}

Peste des petits ruminants (PPR) is a virus that infects mainly goats and sheep. The disease was first described in 1942 in Côte d'Ivoire (Gargadennec, 1942). Small ruminant plague virus (PPRV) was isolated for the first time in 1967 (Bourdin and Laurent-Vautier, 1968). The PPRV is a virus of the family Paramyxoviridae and genusMorbillivirus (Gibbs, et al., 1979). As a disease with economic impact, PPR is on the list of diseases to notify the International Office of Epizootics (OIE, World Animal Health Organization) in the event of emergence. It is now the subject of a global eradication program launched by OIE (International Organization Epizootics) and FAO (Food and Agriculture Organization of the United Nations) (FAO and OIE., 2015). PPRV infection is mostly by contact. The PPRV-related morbidity in a flock can reach $100 \%$ and mortality is estimated at $90 \%$ (Singh, et al., 2009). PPRV genome, composed of a single strand negative RNA with a length of 15, 948 nucleotides that encodes six structural proteins: the nucleoprotein (N), the phosphoprotein $(\mathrm{P})$, the template or matrix protein $(\mathrm{M})$, the fusion protein $(\mathrm{F})$, the hemagglutinin protein $(\mathrm{H})$ and the RNA-dependent viral polymerase (L), as well as two non-structural proteins $\mathrm{C}$ and $\mathrm{V}$ (has no meaning). Apart from the endemic presence of PPR in sub-Saharan Africa from the past decades, in recent years, field data and laboratory findings have confirmed the dramatic spread of PPR towards the south of Africa, affecting Gabon, the Democratic Republic of Congo, Somalia, Kenya and Tanzania. An outbreak of PPR was reported for the first time in October 2012 in Angola and in July 2015 in Zambia (Baron et al. 
2016). The risk of PPR introduction is now high for neighbouring countries with major sheep/goat populations, such as the Republic of South Africa and Mozambique. In addition to the spread in Africa, many Asian countries are now infected, including China. After an initial identification in Tibet in 2007 (Wang et al. 2009), this country experienced a major PPR epizootic in 2013-2014 (Wang et al. 2009). PPRV is classified into 4 genetically distinct lines namely "lineage I" to "lineage IV". The current molecular characterization of PPRV is typically based on the analysis of the partial sequence of the nucleoprotein gene (N, 255 nucleotides, Couacy-Hymann, E. et al., 2002). Lineage I is represented mainly by strains that circulated in West Africa in the 1970s-90s (Figure 1). It was presumed extinct, but a recent article has shown that it circulated in Niger until at least 2001 (Tounkara, K. et al., 2018). Nevertheless, it seems that lineage I has been mostly replaced by lineage II, which has spread throughout West Africa (Ashley C. Banyard et al., 2010). Lineage III is found in East Africa, Sudan, Yemen and Oman. Lineage IV was first identified in India in 1987 (Senthil Kumar, et al., 2014; Parida, et al., 2016), before spreading rapidly in the peninsula in the Middle East and on the African continent (Kwiatek, et al., 2011; Tounkara, et al., 2018; Mantip, et al., 2016). This lineage is currently rapidly spreading in West Africa, notably through extensive and poorly controlled transboundary animal movements (Tounkara et al, 2019; Souley et al 2019).

In Nigeria, sheep and goats are widespread, across different ecological and climatic zones of the country (Figure 2). It is estimated that these animals provide more than $35 \%$ of total animal protein consumption in the country (Mantip, et al., 2016). The total industrial value of small ruminants in Nigeria is around 40 billion naira ( 100 million euros, (Shamaki, 2002). The results obtained in previous studies suggest that PPR remains an endemic disease in the country, accompanied by sporadic epidemics (Shamaki, 2002; Woma, et al., 2016; Mantip, et al., 2016a). In addition, areas where the disease was considered as being exotic in the past are the places today of regular epidemics due to an increase in trade and commerce. Molecular characterization of PPRV based on amplification and sequencing of $\mathrm{N}$ gene fragments in these studies showed the presence of two distinct PPRV lineages: lineage II and IV (Mantip, et al., 2016; Woma, et al., 2016). Due to the consequences of PPRV on production of animals that are of paramount importance to the economy and food security in Nigeria, it is necessary to understand its spread in the country (Mantip, et al., 2016b). In the classification of PPRV strains, there are four genetic lineages based on the sequence of the fusion (F) or nucleoprotein $(\mathrm{N})$ gene (lineages I-IV). Recently, lineage IV was found to circulate alongside lineage II in Nigeria, indicating that at least two different PPRV lineages are currently circulating in Nigeria (Mantip, et al., 2016; Woma, et al., 2016). Lineage IV has historically been found in the Middle East and Asia, but has entered Africa around or before 2000, spreading into several neighbouring countries (Kwiatek, et al., 2011 ; Mantip, et al., 2016). In this study, samples were analysed from 268 small ruminants with PPR symptoms across Nigeria in 2017-2018 to provide an update on the distribution and genetic diversity of the lineage II and IV in the country.

\section{MATERIALS AND METHODS}

\section{Sample collection}

Sampling was conducted between 2017 and 2018 in 18 states in total (Figure 1 and Table S1 in supplementary materials). Veterinarians of national veterinary services conducted the field studies in accordance with local legislation, approval (AEC/02/87/20) was provided by the NVRI Animal Ethics Committee. Still, the tissues used in the study were sourced ethically. In one major market per state, goats and sheep suspected of acute PPR infection were identified based on clinical symptoms that included fever over $40{ }^{\circ} \mathrm{C}$, weight loss, ocular, nasal, or ocular-nasal discharge and diarrhoea. The suspected animals were bought from their owners, euthanized humanely, and subjected to an autopsy to collect tissue samples (lungs and mesenteric lymph nodes). In addition, samples were collected in slaughter houses located near the market from carcasses showing visible symptoms of diarrhoea and oculo-nasal discharges on their carcasses. The samples are then quickly transported to the PPR laboratory of the National Veterinary Research Institute, Vom, Nigeria and placed in a freezer at $-70{ }^{\circ} \mathrm{C}$ before visiting another new state. The samples were then subsequently shipped to CIRAD, Montpellier, France for further analysis in a Biosafety level-3 laboratory facility.

\section{Molecular and phylogenetic analyses}


The total nucleic acids (viral nucleic acids and nucleic acids of the host) were extracted from homogenized tissue samples. The extraction was carried out with an extraction robot KingFisher TM and ID Kit Gene ${ }^{\text {TM }}$ Mag Universal Extraction (IDvet), as described by the manufacturer. An RT-PCR was performed using the qScript XLT One-Step RT-PCR Kit (Quantabio, VWR, France) to amplify a 351 base pair (bp) segment of the PPRV N gene with the NP3/NP4 primer pair modified from Couacy-Hymman, et al., (2002). (Forward NP3: 5'-GTC-TCG-GAA-ATC-GCC-TCA-CAG-ACT-3' and Reverse NP4: 5'-CCT-CCT-CCT-GGT-CCTCCA-GAA-TCT-3') at a final concentration of $0.6 \mu \mathrm{M}$. PCR was set up under the following programme: 50 ${ }^{\circ} \mathrm{C}$ for $30 \mathrm{~min} ; 95{ }^{\circ} \mathrm{C}$ for $15 \mathrm{~min}$ and 40 amplification cycles $\left(10 \mathrm{sec}\right.$ at $95{ }^{\circ} \mathrm{C}, 30 \mathrm{sec}$ at $60{ }^{\circ} \mathrm{C}$ and $30 \mathrm{sec}$ at $72{ }^{\circ} \mathrm{C}$ ) and a final extension step at $72{ }^{\circ} \mathrm{C}$ for $5 \mathrm{~min}$. The PCR products were resolved on $1.5 \%$ agarose gel to reveal the expected band size.

The clean-up and sequencing of positive PCR products in both forward and reverse directions were carried out by Genewiz (United Kingdom). The sequences were submitted to GenBank (Table 1). Forward and reverse DNA sequences were assembled using BioEdit, and trimmed to remove poor-quality portions of the sequences (final size $=255 \mathrm{bp}$ ). Corrected sequences were aligned with different data sets PPRV N gene sequences publicly available in GenBank using MEGA 6. A first dataset contained representatives of the four genetic lineages. Two other datasets contained an increased number of sequences from African lineage II and IV, respectively, to allow for lineage-specific phylogenetic analyses. Phylogenetic trees were constructed using the Maximum Likelihood method as implemented in MEGA 6, with node supports evaluated by bootstrap analyses (1,000 replicates).

\section{RESULTS}

A total of 73 out of 268 animal sampled (27\%) were identified as PPRV positive by RT-PCR (Table 1 and S1). At least one sample was positive for PPRV diagnosis for 17 states: Plateau, Benue, Kwara, Bauchi, Adamawa, Taraba, Katsina, Kebbi, Enugu, Abia, Anambra, Oyo, Ondo, Osun, Rivers, Cross Rivers and Akwa-Ibom. No positive samples out of the twenty (20) tested samples were found for Kano state. Partial $\mathrm{N}$ gene sequence was obtained from all samples. A total of 23 different sequences were obtained (Table 1, Gen-bank accession numbers: MT193234 - MT193256). Phylogenetic analyses showed that the sequence of $72 \mathrm{PPR}$ positive samples belonged to lineage IV. One single sequence from the state of Oyo belonged to lineage II (Figures 1, 2 and S1).

Additional phylogenetic analysis using more extensive lineage II dataset showed the lineage II sequenced obtained clustered with poor node support $(<50 \%)$ with sequences from Senegal and Mauritania (Figure 2). Another lineage II sequence obtained in Oyo state in 2012 was included in a better-supported cluster (68\%) with samples from Ghana. The phylogenetic analysis concentrating on lineage IV showed the presence of multiple well-supported clusters in Nigeria (Figure 4). The two sub-lineages described by Woma and Mantip in 2016 (IV-NigA and IV-NigB) were identified with relatively good support (70-71\%). Phylogenetic relationships were not further resolve for most Nigerian Lineage IV sequences. Still, four clusters were observed within Group IV-NigB, each including 3-5 sequences from multiple states, called here IV-NigB1, IV-NigB2, IV-NigB3 and IV-NigB4 (Figures 1 and 3). Clade IV-NigB1 presented sequences from Ondo, Akwa-Ibom and Enugu. Clade IV-NigB2 brought together sequences of strains harvested in Akwa-Ibom, Benue, Taraba and Cross-River (Figure 3). Clade IV-NigB3 grouped strains from Rivers, Plateau, Benue and Osun with lower support (60\%). Finally clade IV-NigB4 included sequences obtained from Plateau, Kwara, Katsina and Kebbi (support $=62 \%$ ). Only two sequences from Kebbi belonged to sub-lineage IV-NigA. They were closely related to a sample from Niger (Figure 4). Two samples, one from Kebbi in 2018 and one from Osun in 2013 were placed out of sub-lineages IV-NigA and NigB in the tree (Figure 3).

\section{DISCUSSIONS}

In most developing countries, including Nigeria, sheep and goat farming, most especially goat farming is very important and constitutes a vital livelihood for the poorest people. These animals are of paramount important to the economy and the food security of the peasant populations. Among the countries of West Africa, Nigeria has over the years played a preponderant role in the production of small ruminants and 
constitutes a pool of exchanges with frontier countries, in particular for the import of live small ruminants coming from Niger, Chad and Cameroon. The country, whose small ruminant industry is estimated at 100 million euros, represents a major exchange point for animal products in West Africa. These trade and movement of animals is accompanied by the spread of animal diseases, including peste des petits ruminants, of particular economic importance for trade internationally. The disease, extremely contagious and deadly for livestock, is largely spread across the country and threatens sheep and goat populations.

Two studies, both published in 2016, presented results from the analysis phylogeny of the PPRV partial N gene from samples collected in Nigeria (Mantip, et al., 2016; Woma, et al., 2016) based on sampling similar to that of this study, showed the presence of lineage II and lineage IV between 2010 and 2011 in Nigeria. Two sub-lineages of the lineage IV strain were found: a first sub-lineage composed of strains from the states of Plateau, Bauchi, Oyo, Sokoto, Kano, Adamawa, and Kaduna states, while a second sub-lineage composed of strains from Adamawa, Bauchi, Lagos, Kaduna, Plateau, Niger, Oyo and Akwa-Ibom. Woma, et al (2016) also suggested the presence of a lineage group IV to be more important than the lineage II strain, which was until then the dominant lineage found in the country (Shamaki, 2002; Kwiatek, et al., 2007).

This study conducted in Nigeria on samples taken from local markets in 2017 and in 2018 has made it possible to explore, through a phylogenetic study of the PPRV N gene, the different lineages and subgroups of PPRV circulating in the country during this period. These results made it possible to complete and update the information obtained during the studies conducted previously. Thus, it has been established that two different lineages were still circulating in Nigeria between 2017 and 2018: lineage II and lineage IV. The unique sequence of lineage II was found in the state of Oyo. The geographic position of these sequences corroborates what was found previously. Strains of lineage II have already been isolated in this state and neighbouring states, located on the western border of Nigeria. These results remain consistent with what has been found so far, lineage II being still strongly present in West Africa (Tounkara, et al., 2018). The phylogenetic position of this new lineage II sequence is significantly different from the sequences described by Mantip and Woma. This result would suggest that lineage strain II harvested in 2018 could represent a new incursion of the lineage from a neighbouring country and not an evolution of a strain already circulating in the country. Isolation of more lineage II strains in the region and phylogenetic analyses based on longer PPRV sequences would confirm this hypothesis.

The large majority of sequences obtained during this sampling effort belonged to lineage IV, suggesting differences in circulation dynamics of lineage II and IV in Nigeria (possibly associated with hosts and season), or a strong overall dominance of lineage IV in the country. Further sampling, in different type of markets and ruminant populations and at different time would help unravel this issue. The two sub-lineages IVNigA and IV-NigB could be identified again in our study. Only 4 out of 72 samples were infected with strains grouped within sub-lineage IV-NigA. However, recent strains clustering with sub-lineage IV-NigA differ from sequences presented in earlier studies. The sequences found in 2018 were phylogenetically closer to one strain found in Niger in 2013 (Tounkara, et al., 2018). It is difficult to make assumptions about this result. It may correspond to movement of the sub-lineage IV-NigA between Niger and Nigeria, as there are large cross-border transhumance/animal movements in this area, with Niger as the country of departure for most of the flow (Corniaux, 2014).

Furthermore, information on the life of the animal sampled before it arrived in the market would be an asset in a better knowledge of the commercial routes borrowed and therefore of potential movement interfaces of the disease. In addition, knowledge about trade existing between states of the same country but also between countries must be further investigated. The IV-NigA and IV-NigB sub-lineages seem to contain, as demonstrated by Woma and Mantip, statistically significant genetic clusters. In this study, four new genetic clusters were identified within the IV-NigB sub-lineage. These clusters gather samples of different but often neighbouring states, suggesting a circulation of PPR across states. Several of these clusters were found at the same time in the same market which implies a co-circulation of different strains of PPR in the markets. Due to the grouping of animals from different origins in the same markets, these main markets represent a significant risk of transmission and spread of the disease. The IV-NigB2 cluster grouped samples from states 
located along the border with Cameroon. Samples from Cameroon should be obtained to verify if this genetic group is found also on the other side of the border. This north-south axis is also a path of transhumance used seasonally by nomadic pastoralists (Shamaki, D., personal communication, May 2019, Montpellier). In contrast, the lineage IV-NigB4 cluster brings together very distant states, suggesting long-distances PPR spread, possibly associated with animal trade.

Presence of multiple clusters, but also of sequences that did not belonged to any of the two sub-lineages IV-Nig, suggest that the genetic diversity of the lineage IV in Nigeria is probably higher than shown by analyses based on partial N gene sequences. Analyzes based on larger sampling encompassing the entire region, using longer sequences and at best complete genomes of PPRV are necessary to better understand the phylogenetic relationships within PPRV and study the transmission dynamics of the virus in Nigeria and the African region from West. This high genetic diversity in Nigeria may be due to the strategical importance of the country in regional animal trade.

Phylogenetic analysis efforts such as those carried out for this project should continue and be improved. This improvement must take into account the size and the plan of sampling and the information collected from sampled individuals. It should therefore be possible to extend the sampling strategy to better understand the transmission and cross-border spread of the disease. This information may be important for developing appropriate and effective surveillance and control strategies against PPR.

\section{ACKNOWLEDGEMENTS}

The research was supported by internal funds from NVRI (Nigeria) and CIRAD (France), by a grant (SI2.756606) from the European Commission Directorate General for Health and Food Safety awarded to the European Union Reference Laboratory for Peste des Petits Ruminants (EURL-PPR), and by a grant (FOOD/2019/410-957) from the European Union for the project "EU support to Livestock Disease Surveillance Knowledge Integration" (LIDISKI).

\section{ETHICS STATEMENT}

The authors confirm that the ethical policies of the journal have been adhered to and the appropriate ethical review committee approval has been received. The National Veterinary Research Institute, Vom, Nigeria's guideline for the Care and Use of Laboratory Animals were followed.

\section{COMPETING INTERESTS}

The authors declare that they have no financial or personal relationships which may have inappropriately influenced them in writing this article.

\section{AUTHORS' CONTRIBUTION}

S.F. is the project leader. S.F., D.S., A.B., G.L. and S.M. were responsible for experimental and project design. S.M. was responsible for samples collection. A.S. performed some of the experiments. A.B. and S.M. performed most of the experiments and calculations. S.M. prepared, sorted and packaged the samples for shipment from Nigeria to France. S.F., D.S., G.L., A.B. and S.M. made conceptual contributions.

\section{REFERENCES}

Ashley C. Banyard, Satya Parida, Carrie Batten, C. O. and Libeau, O. K. and G. (2010) 'Global distribution of peste des petits ruminants virus and prospects for improved diagnosis and control', Journal of General Virology, 91, p. 2885-2897.

Bourdin, P. \& Laurent-Vautier, A. (1968) 'Note sur la structure du virus de la peste des petits ruminants (in French)", Revue d'élevage et de médecine vétérinaire des pays tropicaux , 20, p. 383-386.

Corniaux, C. (2014) 'The Sahelian cattle trade. An archaic industry or the guarantee of a promising future ?', Contemporary Africa, 249 (1), p. 93-95. doi: 10.3917 / afco.249.0093. 
Couacy-Hymann, E., Roger, F., Hurard, C., Guillou, J. P., Libeau, G. (2002) 'Rapid and sensitive detection of peste des petits ruminants virus by a polymerase chain reaction assay.', J. Virol. Meth., 100, p. 17-25. Available at: https://www.ncbi.nlm.nih.gov/pmc/ (Accessed: 15 November 2017).

FAO and OIE. (2015) 'FAO and OIE International Conference for Control and Eradication of Peste des Petits Ruminants (Abidjan, Ivory Coast).'

Gargadennec L., L. A. (1942) 'La peste des petits ruminants.', Bulletin des Services Zoo Technique et des Epizootie de l'Afrique Occidentale Fran,caise. , 5, p. 16-21. Available at: https://www.ncbi.nlm.nih.gov/pmc/ (Accessed: 16 November 2017).

Gibbs E. P. J., Taylor W. P., Lawman M. J. P., and B. J. (1979) 'Classification of peste des petits ruminants virus as the fourth member of the genus Morbillivirus.', Intervirol. , 11, p. 268 - 274. Available at: https://www.ncbi.nlm.nih.gov/pmc/ (Accessed: 16 November 2017).

Kwiatek, O., Ali, Y.H., Saeed, I.K., Khalafalla, A.I., Mohamed, O.I., Abu Obeida, A., Abdelrahman, M.B., Osman, H.M., Taha, K.M., Abbas, Z., El Harrak, M., Lhor, Y. and Diallo, A., Lancelot, R., Albina, E., Libeau, G. (2011) 'Asian lineage of peste des petits ruminants virus, Africa.', Emerg. Infect. Dis. , 17, p. $1223-1231$.

Kwiatek, O., Minet, C., Grillet, C., Hurard, C., Carlsson, E., Karimov, B. (2007) 'Peste des petits ruminants (PPR) outbreak in Tajikistan.',J. Comp. Path. , 136, p. 111-119. Available at: https://www.ncbi.nlm.nih.gov/pmc/ (Accessed: 16 November 2017).

Mantip, S. et al. (2016) 'Comparison of nucleotide sequences of recent and previous lineages of peste-despetits-ruminants viruses of sheep and goats in Nigeria', Onderstepoort Journal of Veterinary Research , 83(1). doi: 10.4102/ojvr.v83i1.1163.

Mantip, S. et al. (2016a) 'Comparison of nucleotide sequences of recent and previous lineages of peste-des-petits-ruminants viruses of sheep and goats in Nigeria', Onderstepoort $J$ Vet Res . doi: 10.4102/ojvr.v83i1.1163.

Mantip, S. et al. (2016b) 'Comparison of nucleotide sequences of recent and previous lineages of pestedes-petits-ruminants viruses of sheep and goats in Nigeria', Onderstepoort $J$ Vet Res , 83(1). doi: 10.4102/ojvr.v83i1.1163.

Parida, S. et al. (2016) 'Emergence of PPR and its threat to Europe', Small Ruminant Research, 142. doi: 10.1016/j.smallrumres.2016.02.018.

Senthil Kumar, K., Babu, A., Sundarapandian, G., Roy, P., Thangavelu, A., S. K., K., Arumugam, R., Chandran, N.D., Muniraju, M., Mahapatra, M., Banyard, A. C. and Manohar, B.M., Parida, S. (2014) 'Molecular characterization of lineage IV peste des petits ruminants using multi-gene sequence data.', Vet. Microbiol. , 174, p. 39-49.

Shamaki, D. (2002) 'Serological and molecular epidemiology of peste des petits ruminants (PPR) in Nigeria.', Ph. D thesis in the department of Veterinary Microbiology.Univ. of Ibadan. Nigeria.Available at: https://www.ncbi.nlm.nih.gov/pmc/ (Accessed: 17 November 2017).

Singh, R.K., Balamurugan, V., Bhanuprakash, V., Sen, A., Saravanan, P., Pal Yadav, M. (2009) 'Possible control and eradication of peste des petits ruminants from India: technical aspects.', Vet. Ital. , 45, p. 449.

Tounkara, K., Battle, A., Adombi, CM, Maikano, I., Djibo, G., Settypalli, TBK, L. and A., Diallo, A., and Libeau, G. (2018) 'First genetic characterization of Peste des Petits Ruminants from Niger: On the advancing front of the Asian virus lineage.', Transbound. Emerg. Dis. , 65, p. 1145-115.

Woma, T. Y. et al. (2016) 'Co-circulation of Peste-des-Petits-Ruminants Virus Asian lineage IV with Lineage II in Nigeria', Transboundary and Emerging Diseases, 63(3), pp. 235-242. doi: 10.1111/tbed.12387.

\section{Hosted file}


Tables.docx available at https://authorea.com/users/357706/articles/480140-high-geneticdiversity-and-rapid-spread-of-peste-des-petits-ruminants-virus-asian-lineage-iv-innigeria

\section{Hosted file}

Figure 1.docx available at https://authorea.com/users/357706/articles/480140-high-geneticdiversity-and-rapid-spread-of-peste-des-petits-ruminants-virus-asian-lineage-iv-innigeria

\section{Hosted file}

Figure 2.docx available at https://authorea.com/users/357706/articles/480140-high-geneticdiversity-and-rapid-spread-of-peste-des-petits-ruminants-virus-asian-lineage-iv-innigeria

\section{Hosted file}

Figure 3.docx available at https://authorea.com/users/357706/articles/480140-high-geneticdiversity-and-rapid-spread-of-peste-des-petits-ruminants-virus-asian-lineage-iv-innigeria 